\title{
A CONTRIBUIÇÃO DE STUART HALL PARA OS ESTUDOS DE RAÇA E ETNICIDADE NO CINEMA BRASILERO DOS ANOS 1960 E 70
}

\author{
STUART HALL'S CONTRIBUTION TO THE STUDY OF RACE AND \\ ETHNICITY IN THE BRAZILIAN CINEMA OF THE 1960s AND 1970s
}

\author{
LA CONTRIBUCIÓN DE STUART HALL PARA LOS ESTUDIOS DE \\ RAZA Y ETNICIDAD EN EL CINE BRASILEÑO DE LOS AÑOS 1960 Y 70
}

\author{
Pedro Vinicius Asterito Lapera \\ Pesquisador da Fundação Biblioteca Nacional \\ plapera@gmail.com
}

\begin{abstract}
Resumo: Este artigo pretende explorar um panorama da produção cinematográfica brasileira entre os anos 1960 e 70 a partir das representações de raça e de etnia mobilizadas por alguns filmes do período, aliando a isso o referencial intelectual formulado por Stuart Hall em sua obra. Nosso artigo terá como base a seguinte questão: de que modos as ideias de Hall sobre cultura popular e massiva auxiliam-nos a conectar diferentes momentos da história do cinema brasileiro?
\end{abstract}

Palavras-chave: Cinema Brasileiro. Stuart Hall. Estudos de raça/etnicidade

Abstract: This article will explore an panorama of Brazilian film produced between 1960s and 70s, examining representations of race and ethnicity in some films of the period, within the intellectual framework formulated by Stuart Hall in his work. The article will be based on the question: in which ways do Hall's ideas about popular and mass culture help us to connect different moments in the history of Brazilian cinema?

Key words: Brazilian Cinema. Stuart Hall. Race/ethnic studies

Resumen: Este artículo explorará un panorama de la producción cinematográfica brasileña entre los años 1960 y 70 a partir de las representaciones de la raza y la etnicidad presentes en algunas películas de la época, y combinamos al marco intelectual formulado por Stuart Hall en su trabajo. Nuestro artículo se basa en la pregunta: ¿de qué maneras las ideas de Stuart Hall sobre la cultura popular ymassiva ayudan que nosotros conectemos diferentes momentos de la historia del cine brasileño?

Palabras clave: Cine brasileño. Stuart Hall . Estudios de raza/etnicidad

\section{Introdução}


Um panorama pode conter diversos elementos de uma paisagem e de seus aspectos humanos. A ideia de panorama engloba justamente a fusão de elementos que dificilmente seriam considerados isoladamente. Mas essa ideia também pode transmitir a ilusão de que qualquer elemento pode ser incluído ou excluído, naturalizando cânones, apagamentos e hierarquias. No caso do cinema brasileiro, diversos textos panorâmicos debruçaram-se sobre as características nacionais e populares dessa produção. No entanto, estranhamente as dissociaram das questões raciais e/ou étnicas, que foram avaliadas apenas em relação a um determinado filme, mas quase nunca colocadas em perspectiva de modo comparativo.

Considerado um dos pensadores mais influentes a respeito das imbricações entre discurso racial/étnico, cultura popular e cultura de massa, Stuart Hall elaborou ao longo de alguns textos escritos entre as décadas de 1970 e 90 um itinerário que pode nos auxiliar na análise de diversos momentos em que retóricas e estereótipos raciais e étnicos fizeram-se presentes na história do cinema brasileiro. Precisamos afirmar que a historiografia do cinema brasileiro carece de estudos que se debrucem de modo comparado sobre as retóricas raciais e étnicas ativadas pelos filmes e pelos realizadores em todas as fases da cadeia produtiva cinematográfica (pré-produção à exibição).

Este artigo se vale do legado teórico dos Estudos Culturais para compreender como as retóricas dos filmes e dos intelectuais ligados ao cinema brasileiro transformaram-se em relação ao debate sobre o nacional-popular e sobre questões ligadas a raça e a etnicidade. Teremos como objetivo elaborar um breve ensaio historiográfico sobre a produção cinematográfica brasileira entre os anos 1960 e 70 e aproveitar as discussões teóricas de Stuart Hall em torno das noções de cultura, representação e identidade.

Pretendemos analisar de modo panorâmico algumas produções que trataram de questões relacionadas à raça e/ou etnicidade. Para nos ajudar nesse panorama, optaremos por focalizar filmes que trouxeram à narrativa diferentes aspectos das culturas populares no Brasil, tendo em vista que estas foram privilegiadas tanto pelo cinema brasileiro do período quanto pelos Estudos Culturais, sendo um importante ponto de intersecção em nossa análise. Ainda, por conta da dimensão panorâmica desse artigo, preferimos adotar como objeto principal apenas os filmes, em detrimento de textos críticos e/ou documentação referente à cadeia produtiva dos mesmos, que serão no máximo brevemente mencionados. 
Desse modo, lançamos a questão que irá nortear nosso artigo: de que modos as ideias de Hall sobre cultura popular e massiva auxiliam-nos a conectar diferentes momentos da história do cinema brasileiro? Com esta questão, exploraremos um 'panorama dentro de outro panorama', ou seja, partindo da questão do popular, tão fartamente trabalhada pela historiografia do cinema brasileiro, analisaremos o papel das identidades raciais e étnicas na configuração das resistências e, claro, das estratégias de dominação impostas a essas culturas populares. Ao menos, esta é uma tentativa de lidar com o grande 'presente/ausente' dos discursos de raça e etnia na análise dos filmes brasileiros do período.

Existem várias relações possíveis entre a cultura popular e as identidades raciais e étnicas. Em alguns momentos, essas identidades podem aparecer em conflito com o repertório tradicionalmente atribuído ao popular; em outros, podem ser relegadas à marginalidade junto com elementos dessa mesma cultura; ainda, o domínio do popular pode aparecer como um forte referente dessas identidades. Este é um importante ponto de partida para compreender essas dinâmicas nas representações cinematográficas a serem mobilizadas.

Não podemos desconsiderar que o cinema era percebido na época abordada como um campo no qual seus agentes se viam como intelectuais que disputavam legitimidade e autoridade em representar a cultura popular e seus diversos aspectos éticos e estéticos. Logo, a questão da representação da cultura popular será avaliada em paralelo ao papel dos intelectuais ligados ao cinema brasileiro em sua função de mediadores entre essa cultura, o Estado e o público.

\section{Entre o nacional-popular e as identidades étnico-raciais: alguns pontos cegos no panorama do cinema brasileiro dos anos 1960-70}

Como já foi defendido por mim em outro trabalho (Lapera, 2012), o campo do cinema brasileiro entrou na luta discursiva por sua consolidação fortemente amparado pelo discurso do nacional-popular. Por ocasião dos congressos de cinema brasileiro realizados na década de 1950 e da divulgação de filmes importantes para a imagem

pública do cinema brasileiro (e.g. Rio, 40 Graus; O Canto do Mar; Rio, Zona Norte), a ideia de que os filmes produzidos no Brasil deveriam veicular conteúdos que os 
ligassem aos aspectos formadores do povo brasileiro ganhou força política e esteticamente.

Todavia, não podemos perder de vista as tensões entre os intelectuais do campo do cinema brasileiro em torno dessa ideia. Um dos momentos em que essas tensões vieram à tona foi a realização de Bahia de Todos os Santos, dirigido por Trigueirinho Neto entre 1959 e 1960. Centrando sua narrativa na biografia de Tonio (Jurandyr Pimentel), este é apresentado ao espectador dentro do estereótipo do mulato trágico, dividido entre o mundo dos brancos e o dos negros ou, mais precisamente, como Bernardet apontou, "negro para os brancos e branco para os negros"(1978) explicitando o aspecto relacional das identidades (HALL, 2003). A perseguição aos cultos afrobrasileiros e ao movimento grevista dos estivadores no cais do porto de Salvador aparecem como as contrapartidas étnica, racial e de classe de uma repressão historicamente continuada desde os tempos da escravidão. Ainda, há o par interracial entre Tonio e Miss Collins (Lola Brah), que encenam no âmbito privado os antagonismos do ideal da democracia racial.

No filme, a ideologia da democracia racial é contestada principalmente nos diálogos entre as personagens, que sublinham marcadores étnico-raciais em suas interações. Isto é, “a tarefa [da ideologia] de fixar significados através do estabelecimento, por seleção e combinação, de uma cadeia de equivalências" (Hall, 2003 [1985], p. 154) é interrompida por meio da explicitação das identidades raciais das personagens de modo conflituoso. Nas discussões entre Miss Collins e Tonio, toda vez que ela queria desqualificá-lo, chamava-o de "malandro" e o enquadrava em sua identidade racial: "como bebem esses negros" ou ainda, "seu negro maldito!". Em outro momento, quando há a repressão aos ritos afro-brasileiros, os policiais que destroem o terreiro se referem ao candomblé como culto de "gente atrasada".

Podemos afirmar que, em Bahia de Todos os Santos, a cultura popular é representada no "duplo movimento de conter e resistir que se situa em seu interior" (HALL, 2003 [1981], p. 233), na medida em que as personagens precisam lidar com as instâncias estatais que perseguem as religiões populares de matrizes africanas, ao mesmo tempo que conseguem fazer valer a leitura do mundo e das relações sociais a 
partir do parâmetro do candomblé. Assim, o filme evidencia uma rasura ${ }^{1}$ no discurso do nacional-popular para evidenciar uma identidade de ordem étnico-racial.

É interessante para nosso argumento destacar a leitura de Hall da noção de nacional-popular na obra de Gramsci. Ao afirmar que os conceitos de Gramsci deveriam “operar em níveis mais baixos de concretude histórica” (2003 [1986], p. 279), Hall reconheceu o descentramento operado pelo autor na perspectiva economicista do marxismo clássico. Pela leitura de Hall, ao eleger as disputas no âmbito da cultura como o centro de sua preocupação teórica e a retirando da visão determinista dentro do modelo infraestrutura-superestrutura, o nacional-popular foi mobilizado por Gramsci como categoria analítica das dinâmicas culturais entre os dominantes e o povo na busca constante pela hegemonia, uma unidade raramente alcançada. Em seguida, Hall ratifica a centralidade da cultura na análise de Grasmci para destacar que o autor "associa ao nacional-popular toda a gama de questões distintivas" (op. cit., p. 313) na produção de uma cultura popular secular. Por fim, reconhece o paralelismo entre nacional-popular e os discursos em torno de raça e etnia, uma vez que "transferida para situações semelhantes, em que a raça e etnia sempre carregaram poderosas conotações nacionaispopulares ou culturais, a ênfase de Gramsci demonstra ser imensamente esclarecedora" (op. cit, p. 314).

Com isso, destacamos que as representações em torno de raça e etnia - embora silenciadas em muitos momentos - caminharam pari passu com as representações articuladas pelo discurso do nacional-popular no cinema brasileiro. Assim, a produção do mundo social das camadas populares é atravessada nos filmes tanto pela noção de um povo racial e etnicamente integrado como, em outros momentos, categorias raciais e étnicas aparecem misturadas a essa visão de povo, disputando com ela um lugar de autoridade na narrativa das experiências vivenciadas na cultura popular.

Outra experiência cinematográfica em que o nacional-popular pode ser utilizado como chave interpretativa do povo é o filme Cinco vezes favela (1962). Produção do CPC comemorativa dos 25 anos da UNE, é um conjunto de cinco esquetes dirigidos por jovens diretores estreantes ligados ao Cinema Novo: Um favelado (Marcos Farias); Zé da Cachorra (Miguel Borges); Couro de gato (Joaquim Pedro de Andrade); Escola de samba, alegria de viver (Carlos Diegues) e Pedreira de São Diogo (Leon Hirszman).

${ }^{1}$ Stuart Hall e outros teóricos ligados aos Estudos Culturais (sobretudo Homi Bhabha) trabalham com a ideia de rasura, de Derrida, ao analisar ritos da cultura popular/textos/imagens/produtos audiovisuais que questionem as fronteiras das narrativas da nação. 
Valendo-se de diversas práticas discursivas ligadas ao cinema - a "montagem intelectual" eisensteiniana presente no esquete de Hirszman; o cinema clássico narrativo $^{2}$ e o neorrealismo em Couro de gato e em Escola de Samba - o filme em seu conjunto atualiza concepções como "popular" e "nação". Entretanto, alguns esquetes possuem discursos opostos, ora sublinhando a união popular (Pedreira...), ora sua divisão (Um favelado), ora sua alienação (Escola de samba).

Dois episódios do filme merecem destaque em nossa discussão: Escola de samba, alegria de viver e Pedreira de São Diogo. O plot da narrativa do primeiro esquete é a sobrevivência de uma escola de samba, cujos integrantes são interpretados por membros da Unidos do Cabuçu. Ele se inicia com a encenação de uma ameaça a uma jovem negra na descida do morro, feita por um homem mais velho, que convoca mulheres a participarem da ameaça. Mulheres dançam a seu redor ao som de um samba e impedem seu caminho, não sem derrubar panfletos inutilmente recolhidos por ela do chão. Nitidamente, lê-se a convocação à luta operária nos panfletos carregados pela jovem.

Nas duas sequências seguintes, o conflito do filme é apresentado: o homem mais velho da sequência anterior, Babaú (Abdias do Nascimento), é deposto da presidência da escola e é substituído por Gazaneu (Oduvaldo Vianna Filho). Antes disso, fala em tom condenatório à atitude dos outros dirigentes da escola e imputa a eles o futuro fracasso no Carnaval. Mais adiante, Gazaneu discute com a jovem negra intimidada na primeira sequência, revelada então como sua esposa Dalva (Maria da Graça), sendo que a discussão gira em torno da solidariedade de Gazaneu à escola e de Dalva ao sindicato.

A última sequência expõe os efeitos deste choque de solidariedades: Dalva é eleita pela narrativa como a testemunha do fracasso da escola em saldar sua dívida e a punição que isto acarreta. Após subir o morro demonstrando sinais de cansaço físico (coloca as mãos na bacia indicando dor), assiste à briga entre os dirigentes da escola e os agiotas, que culmina na queima do estandarte da escola e na tristeza de seu excompanheiro Gazaneu, então presidente da escola. À Dalva é reservado o posto de consciência popular diante das estratégias de dominação. Com isto, mesmo o repertório da cultura negra legitimado pelas políticas oficiais e por algumas práticas do campo

${ }^{2}$ Categoria analisada por Ismail Xavier em $O$ discurso cinematográfico: a opacidade e a transparência (2005) e que se refere a um conjunto de convenções que visam a tornar a diegese mais próxima possível da percepção humana, tais como a continuidade temporal-espacial; o plano ponto de vista; o uso do closeup. 
cinematográfico (samba) é reposto pelo filme ao lugar da alienação. Mais precisamente, a alienação do povo é o trabalho de representação proposto no esquete.

Em Pedreira de São Diogo, Hirszman elege como motor da narrativa o iminente desabamento de algumas casas de um morro carioca a partir do trabalho de demolição de uma pedreira. Sendo uma das primeiras atuações cinematográficas de Zózimo Bulbul $^{3}$, de acordo com Carvalho (2006), a narrativa torna protagonistas os operários (em sua maioria, negros) que buscam impedir a derrubada dos barracos.

O conflito é apresentado pelo ponto de vista do operário responsável por carregar a tocha que incendeia a corrente de pólvora acionadora das dinamites. Por intermédio dele, barracos muito próximos da pedreira são mostrados. Depois da primeira demolição, a montagem alternada explicita o drama dos operários: o assistente de obras grita para eles o aumento da carga de explosivos e os olhares de espanto são alternados em closes muito rápidos, enquanto a trilha também é bruscamente interrompida, como um prolongamento emocional da reação coletiva. Em seguida, o desânimo de todos é evidenciado pelo silêncio em que permanecem por algum tempo. Dois operários negros (um deles interpretado por Zózimo Bulbul) olham com desalento os barracos no alto da pedreira.

Contudo, a narrativa volta a ser dinâmica a partir do esboço da resistência dos operários diante da notícia. Um dos operários começa a gritar: "precisamos parar isso!". Após uma discussão, surge a ideia de alertar os moradores da favela para ocuparem o alto da pedreira momentos antes de as dinamites serem ativadas. Um deles avisa a uma mulher, que transmite a mensagem aos outros moradores.

O clímax da última sequência é construído a partir da expectativa dos operários em ver os moradores ocupando a pedreira. Uma montagem paralela mostra, de um lado, os moradores sendo avisados e correndo em diferentes direções e, de outro, os operários olhando com aflição para a pedreira. O ritual da demolição segue: um operário toca a corneta, sinal de que outro deve colocar fogo na pólvora. Neste momento, todos os operários olham para o alto. Não há ninguém. A trilha segue a angústia das personagens, inserindo um único instrumento musical em som agudo. De repente, os moradores aparecem no alto da pedreira e a trilha dramática transforma-se em um samba que consagra a união popular. Celebração coletiva entre operários e moradores contraposta à derrota moral imposta ao chefe da obra que ordenara a implosão.

${ }^{3}$ Waldir Onofre, que realizaria na década seguinte seu único longa-metragem, também estreou emCinco Vezes Favela, no episódio Zé da Cachorra, dirigido por Miguel Borges. 
Em perspectiva oposta ao esquete de Diegues, a narrativa de Pedreira... ressalta a capacidade do povo em organizar e criar suas próprias demandas. E usa o mesmo repertório de Diegues - samba - para enaltecer a união popular e não uma suposta alienação da cultura popular perante as relações de poder. Entretanto, ambos partem do pressuposto de um povo racial e etnicamente integrado para sustentar que os conflitos em torno de uma possível mudança social adviriam de sua condição de classe.

Por sua vez, O Pagador de Promessas (1962), adaptação cinematográfica da peça homônima de Dias Gomes, foi dirigido por Anselmo Duarte, então ator e diretor de chanchadas. A trama focaliza a personagem Zé-do-Burro (Leonardo Villar) e sua malograda tentativa de cumprir uma promessa feita em um terreiro de candomblé a Iansã/Santa Bárbara: carregar uma cruz de madeira até o interior da Igreja de Santa Bárbara em Salvador. A trajetória de Zé-do-Burro é negativamente agenciada pelo padre (Dionísio Azevedo), que o impede de entrar na igreja por conta de a promessa ter sido feita em um terreiro, ao que o padre nomeia de "culto ao diabo". Aliada da Igreja, a imprensa também veiculou que Zé-do-Burro era um agitador. Porém, seu desejo de realizar a promessa ganha a simpatia popular de "baianas" (vendedoras de acarajé), mães-de-santo, capoeiras e de uma esquerda política (simbolizada pela personagem do poeta), que passam a aglomerar-se na escadaria da igreja no intuito de convencer o padre a deixá-lo entrar com a cruz.

A narrativa do filme - construída dentro dos parâmetros do cinema clássico narrativo - conferiu a Zé-do-Burro o lugar de herói e, como consequência disso, validou suas visões de mundo no tocante às experiências religiosas. No âmbito da cultura, surgiram tanto a solidariedade popular com seu objetivo de entrar na Igreja com a cruz quanto a insurgência de diversos sujeitos do povo contra essa instituição dominante. E, na medida em que o dissenso entre esses sujeitos populares e a Igreja foi marcado pelo estigma contra o candomblé, evidenciou-se a marca étnica da disputa entre Zé-do-Burro e o padre, num contexto em que "raça e etnia sempre carregaram poderosas conotações nacionais-populares ou culturais", para recordarmos Hall (2003, p.314).

A ratificação das ideias religiosas e do conteúdo étnico do filme na narrativa foram cruciais à recepção do filme pelo campo, uma vez que a crítica especializada e alguns diretores partiram desse elemento para atacá-lo e deslegitimá-lo da autoridade em representar o povo. Seguindo uma orientação de esquerda marxista clássica, em geral, os intelectuais do cinema brasileiro rejeitaram o plot narrativo girar em torno da Igreja Católica como instituição. Ainda,sentiram-se incomodados com o fato de não 
haver nenhuma condenação explícita da visão de mundo cara ao domínio da cultura popular, algo realizado por filmes como Barravento (Glauber Rocha, 1962) ou mesmo Vidas Secas (Nelson Pereira dos Santos, 1963), cujos sucessos perante a crítica apoiaram-se parcialmente nesta característica. A obtenção da Palme d'Or no Festival de Cannes de 1962 contribuiu consideravelmente para a divulgação do filme, como também para a ressonância das críticas feitas a ele.

O conflito da personagem Zé do Burro, por opor diferentes referências religiosas, nunca poderia ser interpretado como um embate intelectual, mas apenas como um resquício de uma mentalidade arcaica. $\mathrm{O}$ erro do filme, na leitura de seus detratores, seria, então, tratar o conflito de crenças religiosas como algo legítimo e não como o mal a ser combatido. Ao legitimar a cultura popular e ao torná-la parte de um espetáculo, o filme chocou-se contra o habitus (BOURDIEU, 2006) que estava sendo negociado no interior do campo cinematográfico, no que se refere ao papel do intelectual e às imagens de um povo a ser transformado e cujas crenças e hábitos religiosos deveriam ser rechaçados.

Comparando Bahia de Todos os Santos, os esquetes analisados de Cinco Vezes Favela e O Pagador de Promessas, é possível deduzir que a religiosidade popular e os ritos e diversões do povo foram o alvo de um processo de estigmatização por parte das instituições representadas (no caso, a polícia, a igreja e a mídia) e, no caso do esquete Escola de samba, alegria de viver e na desqualificação crítica de O Pagador de Promessas, por parte dos intelectuais do campo do cinema brasileiro.

Além disso, em dois dos três filmes mencionados, o Nordeste e sua população foram representados. Essa região também seria o tema da primeira adaptação literária dirigida por Nelson Pereira dos Santos. Vidas Secas (1963), pensada a partir do clássico original de Graciliano Ramos, seria mais uma "visita" do diretor à região, uma vez que já havia filmado Mandacaru Vermelho (1961). Ancorada na narrativa original, o filme inovaria principalmente no uso de uma fotografia estourada pelo cinegrafista Luis Carlos Barreto, apontada pela crítica como o principal ganho estético do filme.

Vidas Secas focaliza o universo de táticas acionadas pelo vaqueiro Fabiano. A preocupação da narrativa em mostrar diferentes momentos em que as personagens aparecem deslocando-se pelo sertão destaca a migração, acionando uma fronteira étnica que caracterizaria a trajetória dos nordestinos pobres. No trabalho de representação (HALL, 1997) elaborado pelo filme, isto é, na produção de significado pela narrativa, a migração revela-se como o momento em que ocorrem as apropriações dos recursos 
disponíveis e estruturados pelas relações de poder. Fabiano instala-se com sua família na casa abandonada, com o intuito de criar gado ou cultivar a terra.

Outros temas que circunscrevem historicamente os nordestinos na produção literária, teatral, cinematográfica, também são trazidos à narrativa de Vidas Secas: a relação com as autoridades locais (coronéis) e com o Estado e a religiosidade popular. O coronel seria o responsável pela expulsão da família de Fabiano ao final do filme, que se apropria do seu referente literário (pela citação da última frase do livro de Graciliano) para situar as personagens em uma panorâmica na qual se afastam lentamente da câmera. Desse modo, a câmera detém-se quase exclusivamente sobre a paisagem árida, potencializando o trabalho de representação de presença/ausência feito pelo filme (família de retirantes/massa de retirantes nordestinos). Desse modo, o drama da migração e o destino da família do vaqueiro Fabiano passa a ser associável por metonímia ao dos retirantes nordestinos, lembrando que "a representação opera tanto pelo que não é mostrado quanto pelo que é” (Hall, 1997, p.59).

A vilania também marcou a construção de outra personagem: o Soldado Amarelo. Em sua interação com Fabiano, é digna de nota a cena de tortura do vaqueiro. Após perder em um jogo de aposta e ter percebido a trapaça do Soldado Amarelo, sua reação é punida com a prisão. Neste ponto, há a uma montagem paralela que mostra a sessão de tortura e a quermesse que acontece em um vilarejo. Sinhá Vitória reza com as crianças na igreja enquanto Fabiano apanha; o ritual do bumba-meu-boi é encenado para o coronel aos sons dos gemidos de dor de Fabiano caído na cela. A alternância entre a felicidade do povo na festa e a dor do vaqueiro evidencia a construção narrativa sobre as práticas da religiosidade popular, novamente colocadas no plano da alienação. Todavia, situa também a resistência à dominação baseada em uma prática popular (o jogo de aposta), explicitando o "duplo movimento de conter e resistir, que inevitavelmente se situa no interior [da cultura popular]" (Hall, 2003 [1986], p. 233).

Pela primeira vez no âmbito do movimento do Cinema Novo, Vidas Secas conseguiu atrair críticas positivas até mesmo de intelectuais que eram considerados seus inimigos públicos, por exemplo os críticos Ely Azeredo e Moniz Vianna. Além disso, participou ao lado de Deus e o Diabo na Terra do Sol do Festival de Cannes de 1964 e obteve alguns prêmios, participando da conquista de prestígio internacional por este movimento.

Após o golpe civil-militar de 1964, os campos artísticos foram alvo de um maior controle por parte do Estado. Finalmente obteve-se a tutela estatal à atividade 
cinematográfica com a criação do INC, em 1966 e da EMBRAFILME, em 1969. Em paralelo, a censura ia paulatinamente exercendo um controle maior sobre a exibição cinematográfica em todo o país, com a centralização da atividade na DCDP (Divisão de Censura de Diversões Públicas), ligada à Polícia Federal durante a ditadura militar.

Neste cenário adverso, em que tanto o financiamento estatal quanto a liberação para que um filme fosse exibido em festivais e comercialmente seguiam as diretrizes da direita então vitoriosa com o golpe, os cineastas viram-se no meio de uma crise de representação político-institucional. Desarticulados após a repressão aos movimentos artísticos e culturais no regime pós-1964, o exílio e até mesmo a prisão de alguns cineastas, estes se viram impelidos a alterar substancialmente sua relação com o domínio da cultura popular.

Um exemplo marcante dessa mudança foi a do próprio Nelson Pereira dos Santos que, dez anos após filmar Vidas Secas, realizou O Amuleto de Ogum (1974). Trazendo o relato ficcional da migração do jovem nordestino branco Gabriel (Ney Sant'anna) para Duque de Caxias, revelou-se fundamental pela abordagem das religiões populares. A narrativa, centrada na trajetória de Gabriel, é contada por Firmino (Jards Macalé), um repentista negro e cego que é cercado por três bandidos. Gabriel vira empregado do chefe criminoso Severiano (Jofre Soares) e é socialmente reconhecido como um "homem de corpo fechado" por um amuleto que carrega em seu peito.

Trazendo à narrativa diversos mitos populares ligados às culturas indígena e negra, o filme expõe a relação das personagens com essas crenças. Seja na relação entre Gabriel e um pai-de-santo, seja no rito de possessão do bandido Severiano por um Exu, por exemplo, o espectador assiste à ligação desse universo religioso com o banditismo presente na Baixada Fluminense. O filme foi percebido por ocasião de seu lançamento e posteriormente enquanto um ponto de virada na carreira do diretor, que então abandonou o pensamento que unia religião e alienação para destacar a primeira no panorama da cultura brasileira e sua importância nas relações sociais. A cultura popular passou a ser vista também no seu potencial de resistência e não apenas a partir da retórica da alienação. A disputa pelo senso comum - qualificado por Hall como "o terreno das concepções e categorias sobre o qual a consciência prática das massas realmente se forma" (2003 [1986], p. 303) - nas culturas populares e, com isso, a explicitação dos tropos raciais e étnicos que a perpassam é tornada central na narrativa de $O$ Amuleto de Ogum. 
$\mathrm{O}$ argumento do filme foi produzido a partir do livro $O$ Amuleto da Morte, de Francisco Santos, um ex-funcionário de Tenório Cavalcanti, político que então dominava a região da Baixada Fluminense. Por ser praticante da umbanda e por explorar os nexos entre religião e banditismo, a obra interessou ao diretor, que obteve os direitos autorais para poder fazer seu filme. Interessante notar que a obra base para o filme tenha sido escrita por um dos retratados na narrativa, o que é mais um índice da mudança do lugar do intelectual, que passa a negociar de forma mais aberta com o domínio da cultura popular que no período anterior ao golpe militar de 1964.

Em várias passagens, encena-se a fusão entre elementos católicos/europeus e africanos como,por exemplo, o momento em que se descobre o poder sobrenatural do protagonista. Após uma discussão com seu chefe Chico de Assis (interpretado pelo próprio Francisco Santos), este dispara contra Gabriel, que mesmo alvejado não é ferido. Neste momento, a imagem ressalta as figuras brancas de São Jorge e de Gabriel no topo e as personagens negras e pardas (os capangas do coronel Severiano, interpretado por Jofre Soares) em sua base. Assim, há o apelo ao sincretismo desses elementos, que ocorrem de forma hierárquica e não casual.

A dimensão hierárquica desse sincretismo fica mais explícita na representação dos pais-de-santo no filme. Pai Erley, da umbanda (culto que funde elementos católicos, indígenas e africanos) é mostrado como uma personagem calma, didática e honesta, sendo que suas explicações ao protagonistas visam engajar afetivamente o espectador no universo da umbanda. Já Gogó, babalorixá do candomblé (culto mais voltado para elementos africanos), é retratado como arruaceiro, sexualmente compulsivo, dado a pequenos golpes e delator do protagonista. Os elementos do sincretismo, "inscritos diferencialmente pelas relações de poder" (Hall, 2003 [1999], p.34) evidenciam a diferença no trabalho de representação das religiões populares: enquanto o candomblé, mais próximo da cultura africana, era tornado antagonista na narrativa (Gogó faz vários feitiços contra Gabriel e se alia a Severiano), a umbanda, já mais distante dos elementos africanos, foi enquadrada como uma crença 'positiva' no filme.

No projeto seguinte encampado por Nelson Pereira dos Santos, As Aventuras amorosas de um padeiro, desta vez como produtor executivo, as consequências da redefinição do papel do intelectual diante do domínio do popular foram ainda mais exacerbadas, no sentido de conferir a Waldir Onofre o lugar de autoridade de ser "o 
primeiro intelectual negro"4 a dirigir um filme. Considerando que Onofre foi o autor do argumento acolhido por Nelson Pereira, o diretor valia-se de uma narrativa de um agente ligado a cultura popular, do mesmo modo que ocorrera com Francisco Santos. Porém, com uma diferença básica nos casos: Onofre já havia sido ator em vários filmes dirigidos pelos cineastas do Cinema Novo e em várias ocasiões falara abertamente do seu desejo em passar à direção cinematográfica.

Assim como Nelson em $O$ Amuleto..., Onofre também articulou gêneros caros a uma cultura massiva, principalmente o melodrama e a comédia erótica. Por ora, concentremo-nos no melodrama. Resumidamente, poderíamos descrever o filme da seguinte forma: a trajetória da jovem suburbana branca Ritinha (Maria do Rosário) que, recém-casada porém infeliz ao lado do marido (Ivan Setta), envolve-se amorosamente primeiro com Seu Marques, um padeiro português (Paulo César Peréio) e depois com Saul, um artista negro (Haroldo de Oliveira), não sem antes projetar-se em uma relação com o operário Tião (interpretado pelo próprio Onofre).

O diretor constrói cenicamente uma denúncia do que nomeia sarcasticamente de "racismo à brasileira". As barreiras cênicas ao romance entre Ritinha e Saul são apresentadas de modo a ressaltar a dimensão racial da opressão imposta ao casal. O primeiro obstáculo é o ressentimento de Seu Marques, mostrado ao espectador como o antagonista principal do casal. A ele cabem as principais agências negativas perante o mesmo: contrata capangas para persegui-lo e, diante de um primeiro fracasso, persevera, para isso envolvendo o advogado e o marido no flagrante de adultério, não sem antes criar uma celebração coletiva do fato, com o auxílio de outras personagens. E é o ressentimentode Seu Marques - aliado ao seu fracasso como amante - que enquadra sua trajetória como melodramática.

Além desta caracterização, outras estratégias melodramáticas presentes em $A s$ Aventuras... podem ser enumeradas: os sonhos de Ritinha; o próprio foco do filme em uma relação amorosa difícil de ser concretizada, sendo isto caro ao gênero, na medida em que este se vale do excesso emocional das narrativas populares, ancorado no sentimento de frustração que impede o contato amoroso entre classes e interracial; o estilo de interpretação e a trajetória da personagem Ritinha, a "vingança" a que são submetidas as personagens do pólo negativo da ação de Saul e Ritinha ao final do filme.

${ }^{4}$ Naverdade, as primeiras realizações de diretores negros ocorreram na década de 1950, por Haroldo Costa e Cajado Filho, de acordo com Carvalho (2006). 
Podemos afirmar que, à organização psíquica oferecida pelo melodrama (BROOKS, 2005), As Aventuras... adiciona a construção de uma imagem de Brasil na qual as relações interétnicas podem ser lidas melodramaticamente. Isto é: embora não haja nenhum tipo de barreira legal às relações interétnicas/interraciais, as barreiras cênicas dirigidas ao casal interracial configuram o foco narrativo de um racismo velado experimentado também pelo espectador.

Neste momento, precisamos fazer uma abordagem comparada em torno da presença das práticas dos cultos afro-brasileiros presentes em O Amuleto de Ogume As Aventuras Amorosas de um padeiro. Em O Amuleto..., encena-se a possessão do chefão Severiano por um Exu. Em close, percebe-se a alteração facial de Severiano, que começa a gritar. Um plano geral capta a corrida de Severiano possuído por um Exu enquanto se contorce e grita de dor. Severiano se joga e se arrasta no chão, no que é amparado pelo pai-de-santo Erley.

A possessão também é elemento central no desenlace de As Aventuras... . Ao longo dela, várias pessoas vão sendo convocadas a ir ver o flagrante de adultério: meninos que assistem a uma partida de futebol, pessoas em um ensaio de escola de samba, fiéis de um terreiro de candomblé e até mesmo transeuntes que acompanham um funeral. A montagem alternada contrasta isso ao diálogo entre Saul (Haroldo de Oliveira) e Ritinha (Maria do Rosário) no ateliê. Após a invasão da casa para o flagrante, o advogado Tola (Procópio Mariano) - aliado do padeiro português perseguidor do casal - vê Saul. Ao reconhecer uma entidade do candomblé, exclama “Saravá!” e a reverencia batendo a cabeça no chão (ao que Saul joga algumas rosas vermelhas), entrando em possessão. O filme é encerrado por um transe coletivo, no qual aparecem várias entidades dos ritos afro-brasileiros: Exu, Pomba-gira, Caboclo etc.

Poderíamos afirmar que as sequências narradas encenam lutas culturais ou seja, um tipo de "luta contínua e necessariamente desigual, por parte da cultura dominante, no sentido desorganizar e reorganizar constantemente a cultura popular" (HALL, 2003 [1981] p. 239). Todavia, essas lutas são mostradas a partir da perspectiva e da vitória moral dos "de baixo", uma vez que os dominantes (no caso, representados pelo industrial, pelo coronel e pela dupla padeiro português/advogado) se vêem constrangidos a aderir à performance dos ritos populares e, mais relevante, a lê-los de acordo com as categorias informadas por seus praticantes.

Em comum, as sequências apresentam duas características da possessão: punição e inversão de hierarquias. E esta inversão apresenta, nos casos analisados, sua marca 
racial ou étnica. No Amuleto..., o chefão branco Severiano é humilhado na frente de seus empregados, o que acarreta em diminuição de seu poder simbólico. Já em As Aventuras..., o personagem do advogado negro Tola é punido por aderir ao discurso do opressor, por tentar negar sua identidade étnica (como adepto do candomblé) e por não se engajar em uma solidariedade racial em relação ao protagonista Saul.

\section{Considerações Finais}

Ao longo deste artigo, valemo-nos do referencial da obra de Stuart Hall para analisar como as culturas populares encontraram-se com o cinema brasileiro dos anos 1960 e 70 na conformação de uma cultura massiva estruturada pelos meios de comunicação e pelo papel ativo do Estado brasileiro na ditadura em regulamentar quais representações da cultura popular seriam consideradas legítimas ou, ao contrário, deveriam ser relegadas ao esquecimento (pela censura ou pela não concessão de financiamento às produções cinematográficas e a sua distribuição, no caso da EMBRAFILME).

No período analisado, verificou-se uma tensão entre o nacional-popular e a formulação de identidades raciais e/ou étnicas, ora pendendo para uma visão homogeneizante de povo, ora reconhecendo as assimetrias e hierarquias presentes nas diferentes identidades. Tanto o discurso do nacional-popular quanto as identidades raciais e/ou étnicas puderam ser percebidos como lugares de resistência no campo cinematográfico frente a uma direita articulada politicamente que se apropriou do Estado, sobretudo após o golpe civil-militar de 64.

A noção de cultura ligada aos discursos do nacional-popular e das identidades raciais e/ou étnicas foi fundamental para estabelecer as transformações desses discursos. Isto é, ao localizar na cultura popular as tensões em torno de sua representação pelos intelectuais ligados ao cinema brasileiro, pretendemos destacar o movimento mais geral de negociação com os ritos do domínio popular sobretudo após a perseguição política às esquerdas advindas com o regime militar. Com essa perseguição, emergiu a crise do intelectual de esquerda, que se mostrou, no caso abordado, uma crise de representação ou, melhor, uma crise no trabalho de representação dessas culturas populares pelos filmes brasileiros. 


\section{Referências}

BERGER, Peter e LUCKMANN, Thomas. A Construção social da realidade. Petrópolis, Vozes, 2004.

BERNARDET, Jean Claude. Cinema brasileiro: propostas para uma história. São Paulo: Paz e Terra, 1978.

BROOKS, Peter. The Melodramatic Imagination: Balzac, Henry James, Melodrama and the mode of excess. Yale University Press: London, 1995.

BOURDIEU, Pierre. O Poder Simbólico. São Paulo, Bertrand Brasil, 2006.

CARVALHO, Noel dos Santos. Cinema e representação racial: o cinema negro de Zózimo Bulbul. Tese defendida junto ao Programa de Pós-Graduação em Sociologia da Universidade de São Paulo, 2006. Orientador: Prof. Dr. Antonio Sérgio Guimarães.

DAMATTA, Roberto. Brasil: uma nação em mudança e uma sociedade imutável? In: Revista Estudos Históricos, Rio de Janeiro, CPDOC, 1988.

HALL, Stuart. A Identidade cultural na pós-modernidade. Rio de Janeiro: DP\&A, 2003.

Da Diáspora: identidades e mediações culturais (Organizadora: Liv Sovik). Belo Horizonte: UFMG, 2003.

The work of representation. In: Stuart Hall (org). Representation:

Cultural Representations and Signifying Practices. Sage: London, 1997.

LAPERA, Pedro Vinicius Asterito. Do preto-e-branco ao colorido: raça e etnicidade no cinema brasileiro dos anos 1950-70. Tese defendida junto ao Programa de PósGraduação em Comunicação da Universidade Federal Fluminense, 2012. Orientação: Prof. Dr. João Luiz Vieira.

XAVIER, Ismail. O discurso cinematográfico: a opacidade e a transparência. São Paulo: Paz e Terra, 2005.

Original recebido em: 22/04/2015

Aceito para publicação em: 05/08/2015

Pedro Vinicius Asterito Lapera

Doutor em Comunicação pelo PPGCOM-UFF e pesquisador da

Fundação Biblioteca Nacional 